\title{
TRANSGENERIDADE FEMININA: UM MAPEAMENTO EM PRODUÇÕES CINEMATOGRÁFICAS
}

\author{
José Adilson da Silva Júnior | UFPE \\ Maria Alice Vasconcelos Rocha | UFRPE/UFPE
}

\section{RESUMO}

O referido estudo tem como objetivo mapear as produções cinematográficas das últimas três décadas próximas passadas que abordam a representação de mulheres transgênero como protagonistas. Este artigo consiste em um recorte da pesquisa de doutorado que considera as roupas das personagens como artefatos vestimentares que, por sua vez, configuram-se como artefatos informacionais utilizados para transmitir informações e significados relacionados à identidade de gênero das mulheres trans representadas nos filmes. A pesquisa qualitativa e exploratória identificou 31 títulos que abordam a transgeneridade feminina sob uma perspectiva identitária no período de 1990-2019. A partir dos resultados obtidos nesta investigação, pretendese extrair o corpus analítico para identificar de que forma a transgeneridade feminina está sendo representada pelo cinema.

Palavras-chave: Transgeneridade; Identidade de Gênero; Vestuário; Cinema; Traje de cena.

\section{Fundamentação Teórica}

\section{Gênero, identidade e expressão de gênero}

Para alguns indivíduos, a vivência de um gênero, masculino ou feminino, pode ser discordante do sexo, biologicamente macho ou fêmea, passando a ser uma questão de identidade, como no caso das travestis e transexuais que são tratadas coletivamente como parte de um grupo designado como transgêneros (JESUS, 2012). Assim, esta pesquisa adota o termo mulheres trans para caracterizar as personagens transexuais e travestis dos filmes encontrados.

Conforme Reis (2018, p. 25), “a identidade de gênero é a percepção que uma pessoa tem de si como sendo do gênero masculino, feminino ou de alguma combinação dos dois, independente de sexo biológico". Trata-se, portanto, da convicção íntima de uma pessoa ser do gênero masculino ou do gênero feminino. Consequentemente, a identidade de gênero de um indivíduo pode não estar visível para as demais pessoas.

Em termos de gênero, todos os seres humanos podem ser enquadrados em duas classificações, podendo ser transgênero ou cisgênero. O cisgênero é o sujeito que se identifica com o gênero 
biológico. Já o transgênero, ou trans, é o indivíduo que não se identifica com o gênero ao qual lhe foi atribuído no nascimento (JESUS, 2012).

Jesus (2012) identifica dois aspectos da dimensão geral sobre os transgêneros, classificando as formas de viver o gênero como: 1| Identidade (transexuais e travestis); 2 | Funcionalidade (transformistas, drag queens, drag kings e crossdressers).

Em princípio, transgêneros são todos os sujeitos cuja identidade de gênero não condiz ao seu sexo biológico. Justamente por não se identificar com o sexo biológico, esses indivíduos sentem um grande desconforto com os seus corpos. Diante disso, submetem-se a terapias hormonais e/ou passam a utilizar roupas características do gênero com o qual se identificam. Em síntese, o termo pode ser empregado para todas as identidades não cisgêneras como transexuais e travestis (LEITE, 2016).

Outro fator relevante dentre os termos e conceitos relacionados ao gênero consiste na expressão (ou performance) de gênero, que compreende em como os indivíduos se apresentam publicamente e demonstram seu gênero em sociedade, seja por meio do seu nome, pelo comportamento, pela forma de agir e interagir com as demais pessoas, pelo corte de cabelo ou pela vestimenta, contemplando desde o uso de roupas e acessórios, bem como por características corporais, gestos, atitudes e pelo timbre de voz (REIS, 2018).

De acordo com Wittmann (2019), as roupas são responsáveis pela criação e manutenção de uma série de signos dentro do contexto em que são inseridas, como a representação de identidade, não só de gênero, mas de grupo e de classe social.

As roupas ajudam a criar sentido, reforçar hierarquias e construir verdades. Especialmente quando se refere ao gênero, o vestuário com valor de moda passa a funcionar como uma espécie de substituto da anatomia, visto que, ao mesmo tempo que oculta, ele anuncia as diferenças. A incompatibilidade dos gêneros, embora rompida em vários momentos ao longo da história da moda, é notoriamente reforçada pelas roupas (ARCOVERDE, 2018).

Conforme afirma Affonso (2012, p. 22), "a moda estabelece o seu lugar como importante contribuinte social, aderindo e construindo interfaces com outras áreas do saber, como os transexuais e transgêneros".

Butler (2018) discute sobre a performatividade de gênero e, segundo a autora, o gênero é um gesto performativo que produz significado a partir, dentre outros elementos, do uso das roupas. Bento 
(2006, p. 179) corrobora deste pensamento ao afirmar que "vestir-se é um dos atos performáticos mais carregados de significados para a construção das performances dos gêneros".

Logo, o gênero é uma construção social que faz parte da cultura e não da biologia (COUTINHO, 2012). Neste contexto, a roupa permite expressar a identidade de gênero e ela antecede qualquer modificação corporal e adianta o processo de transformação profunda, a fim de construir e ao mesmo tempo desconstruir o gênero. A roupa é o primeiro passo pelo qual uma pessoa trans irá recorrer, mesmo antes das modificações corporais, para dar início a sua transição. Ela vai auxiliar na afirmação do seu próprio ser e de sua existência para o convívio social e, principalmente, da satisfação pessoal (AFFONSO, 2012).

As pessoas trans aderem ao vestuário como forma de se apresentar e expor o seu gênero através do ato de se vestir e isso está estritamente relacionado com a expressão de gênero. As roupas são signos de gênero importantes na cultura, pois uma de suas funções é, ainda hoje, regular as fronteiras entre gêneros e grupos sociais. A roupa torna-se, portanto, principiante no processo de construção da identidade de gênero, permitindo que as pessoas possam se expressar, conforme a sua essência.

\section{Representações da transgeneridade no audiovisual}

De acordo com Carvalho (2021), há, no imagético brasileiro, uma ideia pré-determinada do que é ser uma pessoa trans/travesti. Segundo a autora, existe uma construção social legitimada pelas ciências, judiciário, religião e pelo próprio Estado que afirmam essas imagens/narrativas. Esse conjunto de imagens vem sendo continuamente reproduzido pelas artes e pela mídia através do rádio, jornais, revistas, literatura, teatro, música, cinema, e, principalmente, pela televisão que, há décadas, é “o principal meio de informação e comunicação de massa através do qual muitas pessoas não-trans tiveram contato/conhecimento sobre pessoas trans/travestis pela primeira vez" (CARVALHO, 2021, p. 102).

Comumente, essa construção social, expressa por esse conjunto de imagens, carrega um grande teor de estereótipos. Ao falar sobre esses estereótipos, Carvalho (2021, p. 102) afirma que o humor transfóbico faz "uma associação perigosa da travestilidade/transexualidade como algo caricato, risível, negativo, falso, patológico, sexual, criminal, com moralidade inferior e/ou ausência de humanidade". 
Ferreira Silva et al. (2018), em uma abordagem da transgeneridade, analisaram a representação da identidade do eu e do estigma em produções audiovisuais recentes, mais precisamente através de cinco documentários datados de 2013 a 2016. A partir disso, os autores concluíram que:

\begin{abstract}
As identidades trans, quando expressadas na sociedade, tendem a empurrar os sujeitos à estigmatização e ao preconceito, que determinam uma posição de desvantagem nas relações. Este processo repercute no modo como essas pessoas vivenciam sua identidade do eu, dado que sua percepção de si parte do olhar do outro. Ficou evidente que elas passam por diversas configurações da sua imagem como forma de corporificar sua identidade (FERREIRA SILVA et al., 2018, p. 140).
\end{abstract}

Em outro estudo, Silva (2018) buscou mapear e examinar como a transgeneridade é produzida no cinema. $\mathrm{O}$ autor identificou, portanto, a existência de três regularidades recorrentes que emergiram do mapeamento realizado, as quais caracterizam como as produções cinematográficas costumam abordar a transgeneridade. Segundo Silva (2018), a violência, a nudez e a precariedade foram as três recorrências que se configuraram tanto nas narrativas, quanto no emprego dos recursos formais de produção da transgeneridade no material fílmico analisado. As três regularidades encontradas pelo autor - com destaque para a violência, a que mais se sobressaiu em relação às outras demonstraram que o corpo trans perturba e desestabiliza as relações de poder que produzem os corpos normativos (SILVA, 2018, p. 151).

Por fim, voltando à pesquisa de Carvalho (2021), a autora destaca as cinco principais narrativas, estereótipos e arquétipos sobre a representação de pessoas trans/travestis na arte e no humor, a saber: 1 | da estética (estética masculina, estética do exagero, e estética da ausência); 2 | da farsa; 3 | criminal; 4 | sexual; 5 | da vergonha.

Por conseguinte, a partir dos apontamentos feitos por Silva (2018), conseguimos identificar algumas semelhanças com o que é apontado por Carvalho (2021), sendo possível equiparar a recorrência da violência com a narrativa criminal, bem como a recorrência da nudez com o estereótipo sexual. Assim, os indicadores aqui narrados serão considerados nos procedimentos metodológicos descritos a seguir.

\title{
2. Métodos
}

A corrente pesquisa, de abordagem qualitativa, adota o método de abordagem indutivo. Este estudo lança mão do método de procedimento monográfico, uma vez que estuda um determinado grupo de indivíduos pertencentes à comunidade LGBTQIA+', com a finalidade de obter generalizações.

Esta pesquisa, de cunho exploratório, foi realizada com o intuito de mapear as produções cinematográficas que abordam a transgeneridade feminina. Dessarte, a produção cinematográfica 
das três últimas décadas relacionada ao tema proposto foi obtida por meio de vários recursos. Os resultados foram alcançados por meio de consulta a sites de busca como o Google, canais do YouTube, lista de usuários no site Filmow, artigos científicos, dissertações e teses acadêmicas.

\section{Discussão}

A partir da realização da pesquisa exploratória, foram encontradas 50 produções cinematográficas. No sentido do refinamento, como primeiro critério de exclusão, foi definido que os documentários não seriam considerados para compor o corpus analítico desta investigação, pois caracterizam-se pela exploração da realidade. Logo, a realidade não faz parte do escopo desta pesquisa, uma vez que buscará analisar de que forma a transgeneridade feminina vem sendo comunicada no cinema de ficção (ou ficcional) a partir do traje de cena das personagens.

Como segundo critério de exclusão, filmes que abordam uma vivência de gênero funcional (transformistas, drag queens e crossdressers) também foram desconsiderados. Estas experiências de gênero, definidas por Jesus (2012) como Funcionalidade, se distanciam dos objetivos da pesquisa que priorizam a vivência do gênero como Identidade (transexuais e travestis).

Desse modo, após a adoção dos critérios de exclusão, permaneceram como corpus desta pesquisa um total de 31 filmes que abordam a transgeneridade feminina através da vivência de gênero identitária (transexuais e travestis) em filmes de ficção, conforme mostra o Quadro 1 a seguir:

Quadro 1: Filmes encontrados organizados de acordo com as décadas.

\begin{tabular}{|c|c|c|}
\hline \multicolumn{3}{|c|}{ FILMES POR DÉCADA } \\
\hline $1990-1999$ & $2000-2009$ & $2010-2019$ \\
\hline Traídos pelo Desejo (1992) & $\begin{array}{l}\text { Hedwig - Rock, Amor e Traição } \\
\qquad(2001)\end{array}$ & Elvis \& Madona (2010) \\
\hline Priscilla, a Rainha do Deserto (1994) & Princesa (2001) & Gun Hill Road (2011) \\
\hline \multirow[t]{13}{*}{ Tudo Sobre Minha Mãe (1999) } & A Luta Pela Beleza (2003) & Mía (2011) \\
\hline & Normal (2003) & Laurence Anyways (2012) \\
\hline & Tirésia (2003) & Clube de Compras Dallas (2013) \\
\hline & Um Amor na Trincheira (2003) & Boy Meets Girl (2014) \\
\hline & Lado Selvagem (2004) & A Garota Dinamarquesa (2015) \\
\hline & Má Educação (2004) & Tangerina (2015) \\
\hline & Café da Manhã em Plutão (2005) & A Glória e a Graça (2017) \\
\hline & Transamérica (2005) & Uma Mulher Fantástica (2017) \\
\hline & 20 Centímetros (2005) & Entre Laços (2017) \\
\hline & $\begin{array}{l}\text { A Girl Like Me - The Gwen Araujo } \\
\text { Story (2006) }\end{array}$ & Girl (2018) \\
\hline & Além do Desejo (2006) & Alice Júnior (2019) \\
\hline & Quanto Dura o Amor? (2009) & \\
\hline & Strella (2009) & \\
\hline
\end{tabular}


Considerando que esta pesquisa ainda está em andamento, os títulos listados no Quadro 1, passarão por uma triagem para definição do corpus analítico da tese de doutorado em construção. Pretendese selecionar três filmes de cada década, para identificar e analisar a representação de mulheres transgênero a partir dos artefatos vestimentares, compreendidos como artefatos informacionais constituídos a partir das roupas e acessórios ou todo e qualquer objeto que seja utilizado diretamente sobre o corpo das personagens trans.

Inicialmente, foi necessário estabelecer um critério primordial para delimitar que traços de transgeneridade serão considerados. Logo, como já afirmado anteriormente, esta pesquisa centraliza suas análises na transgeneridade a partir de uma vivência identitária (JESUS, 2012), excluindo assim, filmes que abordem discussões sobre drag queens, transformistas e crossdressers.

A seguir, está exposta uma breve amostra dos artefatos vestimentares de alguns dos filmes que poderão compor o corpus analítico da continuidade desse estudo, onde cada imagem representa uma das décadas consideradas nesta pesquisa.
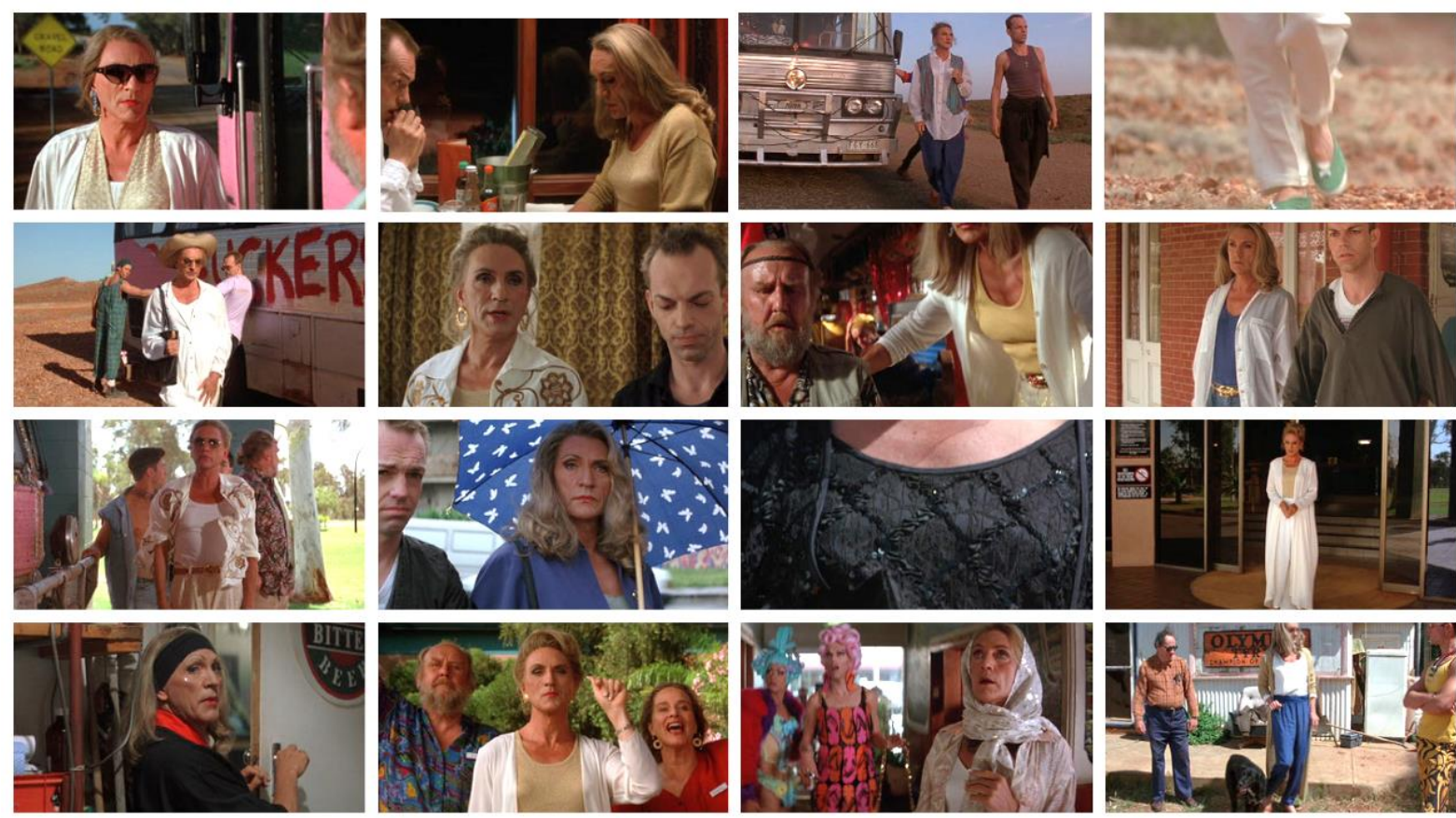

Figura 1. Prévia dos artefatos vestimentares do filme Priscilla, a Rainha do Deserto, 1994. Fonte: Autoria própria a partir de capturas de tela do filme Priscilla, a Rainha do Deserto (2021). 

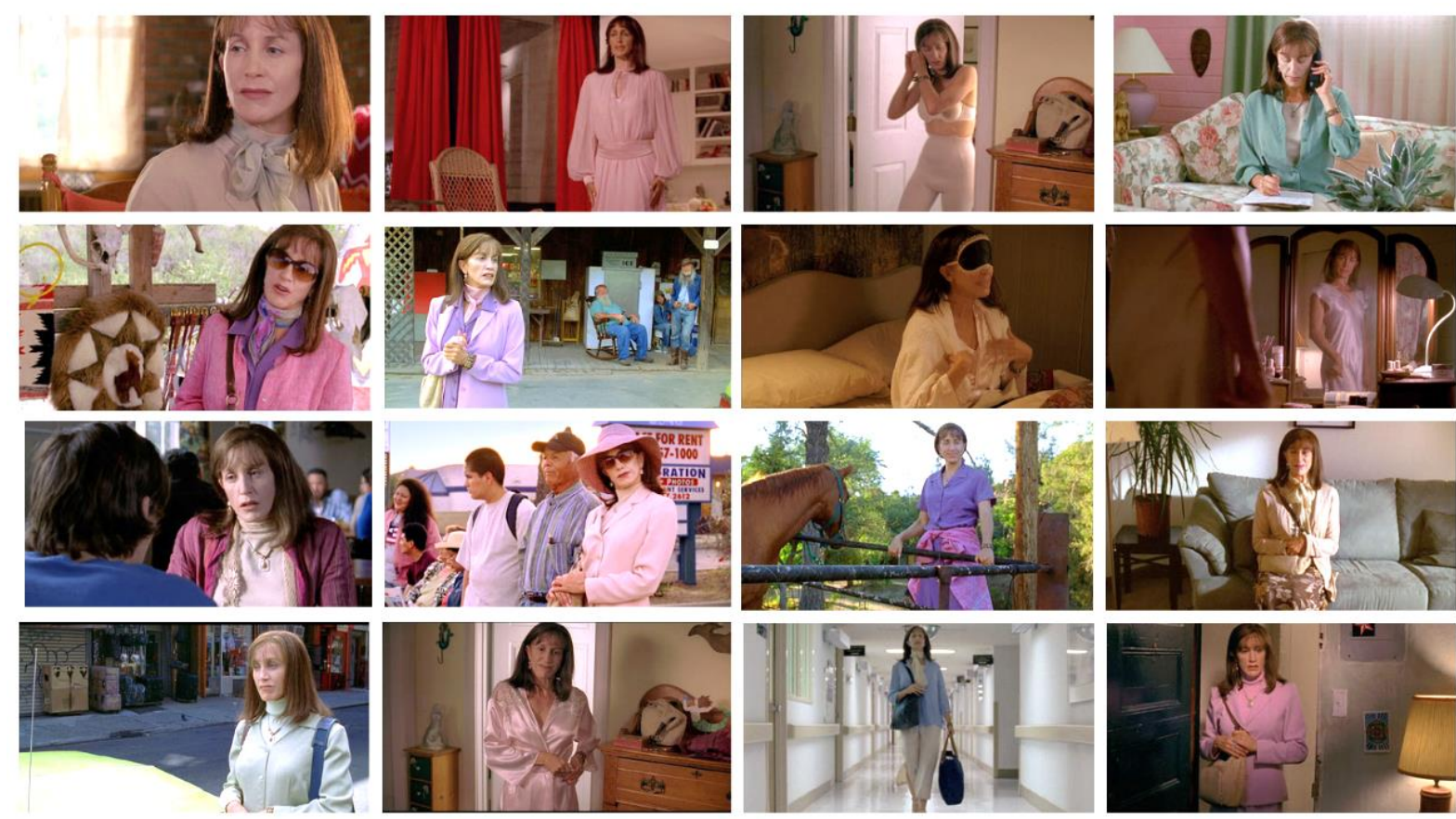

Figura 2. Prévia dos artefatos vestimentares do filme Transamérica, 2005.

Fonte: Autoria própria a partir de capturas de tela do filme Transamérica (2021).
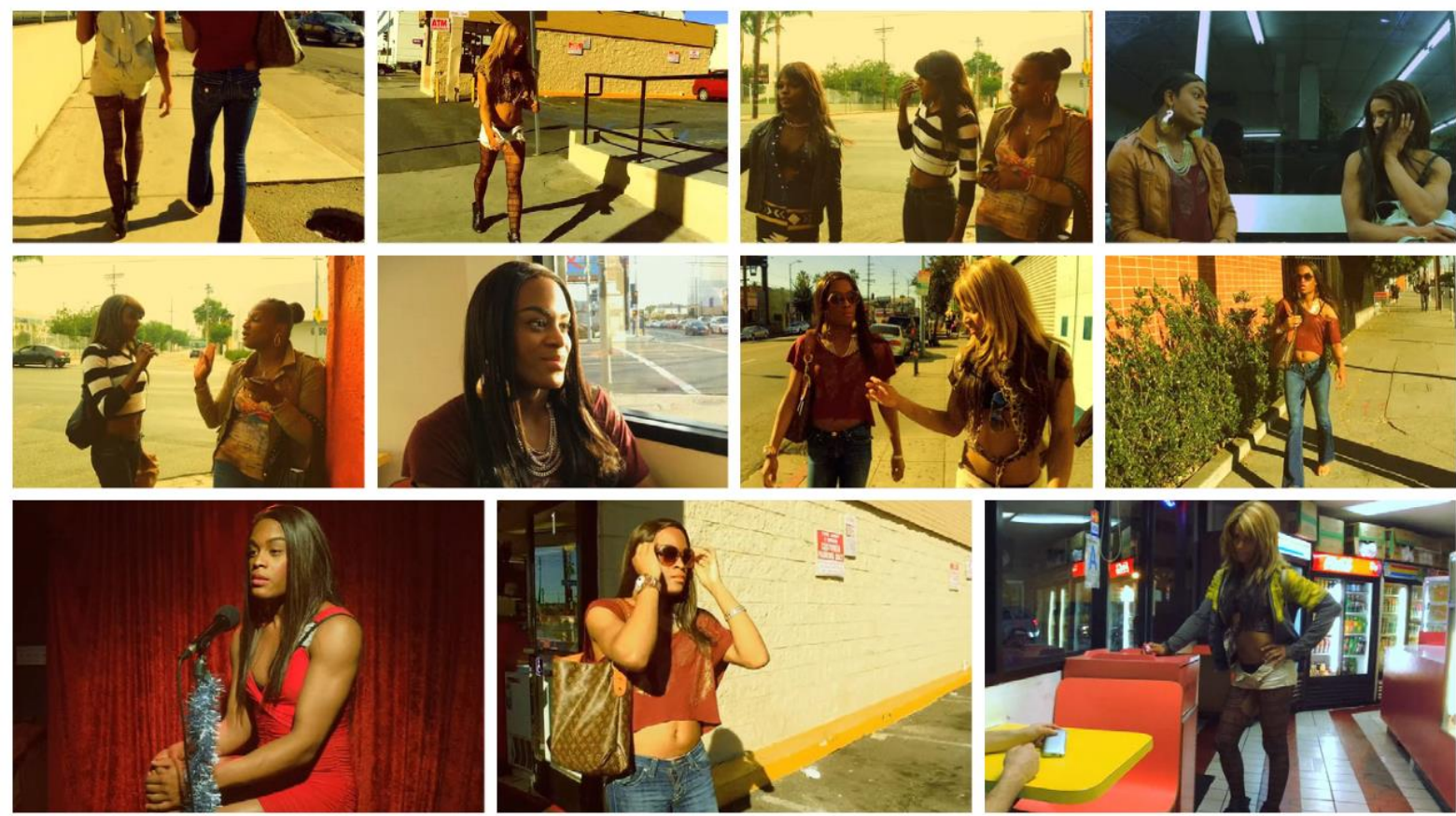

Figura 3. Prévia dos artefatos vestimentares do filme Tangerina, 2015. Fonte: Autoria própria a partir de capturas de tela do filme Tangerina (2021).

A realização da investigação também permitiu a identificação da prática do transfake em grande parte dos filmes mapeados. Este termo refere-se à prática de atores cisgênero, pessoas que se reconhecem no gênero de nascimento, interpretarem personagens trans e travestis, pessoas que não 
se identificam com o gênero de nascimento. 0 Quadro 2, a seguir, detalha os 31 filmes inicialmente elegidos, trazendo informações acerca do nome das personagens trans, os atores ou atrizes que as interpretaram e se houve ou não a prática do transfake.

Quadro 2: Filmes organizados de acordo com as décadas com indicação da prática do transfake.

\begin{tabular}{|c|c|c|c|c|}
\hline & FILME & PERSONAGEM & ATOR/ATRIZ & TRANSFAKE \\
\hline \multirow{3}{*}{ 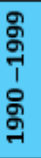 } & Traídos pelo Desejo (1992) & Dill & Jaye Davidson & Sim \\
\hline & Priscilla, a Rainha do Deserto (1994) & Bernadette & Terence Stamp & Sim \\
\hline & Tudo Sobre Minha Mãe (1999) & $\begin{array}{l}\text { Agrado } \\
\text { Lola }\end{array}$ & $\begin{array}{c}\text { Antonia San Juan } \\
\text { Toni Cantó }\end{array}$ & $\begin{array}{l}\text { Sim } \\
\text { Sim }\end{array}$ \\
\hline \multirow{15}{*}{ 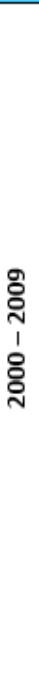 } & Hedwig - Rock, Amor e Traição (2001) & Hedwig Robinson & John Cameron Mitchell & Sim \\
\hline & Princesa (2001) & Fernanda & Ingrid de Souza & Não \\
\hline & A Luta Pela Beleza (2003) & Nong Toom & Asanee Suwan & Sim \\
\hline & Normal (2003) & Ruth Applewood & Tom Wilkinson & Sim \\
\hline & Tirésia (2003) & Tiresia I & Clara Choveaux & Sim \\
\hline & Um Amor na Trincheira (2003) & Calpernia Addams & Lee Pace & Sim \\
\hline & Lado Selvagem (2004) & Stéphanie & Stéphanie Michelini & Não \\
\hline & Má Educação (2004) & $\begin{array}{l}\text { Zahara } \\
\text { Ignacio }\end{array}$ & $\begin{array}{c}\text { Gael García Bernal } \\
\text { Francisco Boira }\end{array}$ & $\begin{array}{l}\text { Sim } \\
\text { Sim }\end{array}$ \\
\hline & Café da Manhã em Plutão (2005) & Patrick & Cillian Murphy & Sim \\
\hline & Transamérica (2005) & Bree Osbourne & Felicity Huffman & Sim \\
\hline & 20 Centímetros (2005) & Marieta & Mónica Cervera & Sim \\
\hline & A Girl Like Me - The Gwen Araujo Story (2006) & Gwen Araujo & J. D. Pardo & Sim \\
\hline & Além do Desejo (2006) & Veronica & David Dencik & Sim \\
\hline & Quanto Dura o Amor? (2009) & Suzana & Maria Clara Spinelli & Não \\
\hline & Strella (2009) & Strella & Mina Orfanou & Não \\
\hline \multirow{13}{*}{ 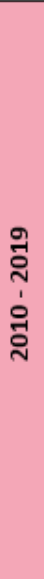 } & Elvis \& Madona (2010) & Madona & Igor Cotrim & Sim \\
\hline & Gun Hill Road (2011) & Vanessa Rodriguez & Harmony Santana & Não \\
\hline & Mía (2011) & Ale & Camila Sosa Villada & Não \\
\hline & Laurence Anyways (2012) & Laurence Alia & Melvil Poupaud & Sim \\
\hline & Clube de Compras Dallas (2013) & Rayon & Jared Leto & Sim \\
\hline & Boy Meets Girl (2014) & Ricky Jones & Michelle Hendley & Não \\
\hline & A Garota Dinamarquesa (2015) & Lili Elbe & Eddie Redmayne & Sim \\
\hline & Tangerina (2015) & $\begin{array}{c}\text { Sin-Dee } \\
\text { Alexandra }\end{array}$ & $\begin{array}{c}\text { Kitana Kiki Rodriguez } \\
\text { Mya Taylor }\end{array}$ & $\begin{array}{l}\text { Não } \\
\text { Não }\end{array}$ \\
\hline & A Glória e a Graça (2017) & Glória & Carolina Ferraz & Sim \\
\hline & Uma Mulher Fantástica (2017) & Marina Vidal & Daniela Vega & Não \\
\hline & Entre Laços (2017) & Rinko & Toma Ikuta & Sim \\
\hline & Girl (2018) & Lara & Victor Polster & Sim \\
\hline & Alice Júnior (2019) & Alice & Anne Celestino & Não \\
\hline
\end{tabular}

Conforme pode ser observado no Quadro 2, 21 das 31 produções recorreram ao transfake, isto é, atores e atrizes cisgênero (homens e mulheres) interpretaram personagens trans e travestis. Deste modo, apenas em 10 filmes observou-se que as personagens trans de fato foram interpretadas por mulheres transgênero. Consequentemente, pode-se perceber que o cinema ainda confia a maioria dos papéis trans a atores cisgêneros. Considera-se, portanto, que a prática do transfake se afasta do artefato roupa, mas que pode conter significados importantes nas análises futuras a serem desenvolvidas. 


\section{Conclusão}

A partir dos filmes catalogados, pretende-se analisar, através dos artefatos vestimentares das personagens trans, de que forma a transgeneridade feminina vem sendo retratada no cinema das últimas três décadas (1990-1999, 2000-2009, 2010-2019). Para tanto, a pesquisa está alicerçada em duas grandes áreas do Design, a saber: 1| Design de Moda, no que tange ao vestuário a partir dos artefatos vestimentares (inclui roupas, calçados e acessórios com valor de moda ou todo e qualquer objeto que seja usado diretamente sobre o corpo) utilizados pelas personagens trans; 2 | Design da Informação, responsável pela identificação dos elementos visuais comunicados através dos signos presentes nas roupas e acessórios das personagens.

Compreende-se que, a partir do momento que os artefatos vestimentares transmitem mensagens e informações visuais sobre a identidade de gênero das personagens trans dos filmes mapeados, eles se configuram como artefatos informacionais.

Os resultados obtidos, com esta investigação, poderão fornecer subsídios importantes para uma reflexão sobre o papel social do design como construtor de valores e representação por meio do vestuário e da linguagem visual.

\section{Referências}

AFFONSO, F. P. Transgeneridade na moda: o vestir em João Nery e Laerte Coutinho. Monografia. Curso de Especialização em Moda, Cultura de Moda e Arte. Instituto de Arte e Design - Universidade Federal de Juiz de Fora, 2012. Disponível em:

<https://www.ufjf.br/posmoda/files/2013/05/Transgeneridade-na-moda.pdf>. Acesso em 15 set. 2020.

ARCOVERDE, M. Costuras invisíveis: moda e (des)construção do gênero. In: ComCiência - Revista Eletrônica de Jornalismo Científico. Dossiê Moda, out. 2018. Disponível em:

$<$ https://www.comciencia.br/costuras-invisiveis-moda-e-desconstrucao-do-genero/>. Acesso em 04 fev. 2021.

BENTO, B. A reinvenção do corpo: sexualidade e gênero na experiência transexual. Rio de Janeiro: Garamond, 2006.

BUTLER, J. Problemas de gênero: feminismo e subversão da identidade. 16a ed. Rio de Janeiro: Civilização Brasileira, 2018.

CARVALHO, R. A transfobia recreativa e o corpo risível. In: BENEVIDES, B. G.; NOGUEIRA, S. N. B. Dossiê dos assassinatos e da violência contra travestis e transexuais brasileiras em 2020. São Paulo: Expressão Popular, ANTRA, IBTE, 2021.

COUTINHO, L. Entrevista com Laerte. Itaú Cultural. 2012. Disponível em:

<http://novo.itaucultural.org.br/materialcontinium/me-trate-comrespeito/>. Acesso em 19 jul. 2019. 
FERREIRA SILVA, A. C. F. S. C.; GOIS CAVALCANTE, B. L. G. C.; DUARTE, C. A. D.; MADRUGA MONTEIRO, L. Transgeneridade: uma análise da representação da identidade do eu e do estigma nas produções audiovisuais recentes. In: Revista Ártemis - Estudos de Gênero, Feminismos e Sexualidades, v. 24, n. 1, p. 132-142, 12 jan. 2018.

JESUS, J. G. Orientações sobre identidade de gênero: conceitos e termos. Brasília: Publicação online, abr. 2012. Disponível em: <http://www.diversidadesexual.com.br/wpcontent/uploads/2013/04/G\%C3\%8ANERO-CONCEITOS-E-TERMOS.pdf>. Acesso em 29 mar. 2018.

LEITE, H. Transexual, travesti, drag queen... qual é a diferença? Correio Braziliense. 2016. Disponível em: <http://especiais.correiobraziliense.com.br/transexual-travesti-drag-queen-qual-e-a-diferenca>. Acesso em 22 set. 2020.

REIS, T., org. Manual de Comunicação LGBTI+. 2ª edição. Curitiba: Aliança Nacional LGBTI / GayLatino, 2018.

SILVA, C. R. Corpos (trans)formados no cinema. Dissertação (Mestrado). Curso de Pós-Graduação em Comunicação e Informação. Universidade Federal do Rio Grande do Sul. Porto Alegre, 2018.

WITTMANN, I. A roupa expressa a identidade: moda enquanto tecnologia de gênero na experiencia transgênero. In: Cadernos de Arte e Antropologia, vol. 8, no 1/2019, pag. 77-90. Disponível em: $<$ https://journals.openedition.org/cadernosaa/2018?file=1>. Acesso em 02 fev. 2021.

' Lésbicas, Gays, Bissexuais, Transexuais, Queer, Intersexo, Assexuais e o + é utilizado para incluir outros grupos e variações de sexualidade e gênero. 